Çukurova Üniversitesi Mühendislik Mimarlık Fakültesi Dergisi, 33(4), ss. 241-254, Aralık 2018

Çukurova University Journal of the Faculty of Engineering and Architecture, 33(4), pp. 241-254, December 2018

\title{
İş Sürekliliği Yönetiminde Kritik Başarı Faktörlerinin AHP Yöntemi ile Önceliklendirilmesi
}

\author{
Melek NAR ${ }^{1}$, Oya Hacire YÜREGÍR ${ }^{* 1}$ \\ ${ }^{1}$ Çukurova Üniversitesi, Mühendislik Fakültesi, Endüstri Mühendisliği Bölümü, Adana \\ Geliş tarihi: 13.03.2018 Kabul tarihi: 25.12.2018
}

$\ddot{O} \mathbf{z}$

İş sürekliliği planlaması, işletmelerin herhangi bir felaket veya iş kesintisi anında sahip olduğu varlıkları korumasını amaçlayan ve kabul edilebilir bir seviyede hizmet vermeye devam etmesini sağlayan süreçlerin yönetimidir. Kritik başarı faktörleri (KBF) ise, işletme süreçlerinin başarılı olması için olmazsa olmaz faktörler olarak tanımlanabilmektedir. Bu çalışmada, ilk olarak iş sürekliliği yönetimindeki KBF'lerin önceliklerini ortaya koyacak şekilde bir anket hazırlanmıştır. Daha sonra, AHP (Analitik Hiyerarşi Prosesi) modeli için ana ve alt kriterlerden oluşan hiyerarşik yapı geliştirilmiştir. İlgili ankette; planlama, tedbir, sorumluluk olmak üzere üç adet ana kriter ele alınırken, on üç adet alt kriter incelenmiş̧ir. Karar alternatifleri olarak altı adet KBF belirlenmiştir: üst yönetim desteği, iş etki ve risk analizi, teknolojik altyapı, eğitim ve bilgilendirme, metodoloji, sürdürülebilirlik proje yönetimi.

AHP tekniği ile, hem nitel hem de nicel verileri kullanarak, iş sürekliliği yönetiminde KBF'lerin önceliklendirilmesine imkan sağlayan geliştirilen bu model ile birinci öncelikli kritik başarı faktörünün metodoloji ve proje yönetimi faktörü olduğu görülmüştür.

Anahtar Kelimeler: İşs sürekliliği planı, İş etki analizi, Risk analizi, Analitik hiyerarşi prosesi, Kritik başarı faktörü

\section{Prioritization of Critical Success Factors in Business Continuity Management with AHP Method}

\begin{abstract}
Business continuity planning is a management of processes that ensure services to business partners at an acceptable level and protect assets during the event of a disaster or business interruption. Critical success factors (CSFs) can be defined as essential factors for successful business operations.

In this study, firstly, a survey was prepared to set the priorities of critical success factors in business continuity management. Subsequently, a hierarchical structure for the AHP model including main and sub criteria was developed. In the survey; three main criteria as planning, precaution and responsibility, and thirteen sub-criteria were examined. Six CSFs have been identified in business continuity management as decision alternatives: top management support, business impact and risk analysis, technological infrastructure, education, methodology and project managament, sustainability. With this model, which enables prioritization of CSFs in business continuity management using both qualitative and quantitative
\end{abstract}

*Sorumlu yazar (Corresponding author): Oya Hacire YÜREGİR, oyuregir@yahoo.com 
data with AHP technique, it is seen that the first priority critical success factor is the methodology and project management factor.

Keywords: Business continuity planning, Business impact analysis, Risk analysis, Analytical hierarchy process, Critical success factor

\section{GİRIŞ}

İş sürekliliği, işletmelerin kritik iş süreçlerinin sürekliliğine olanak vermek, sağlanamadığı durumlarda kabul edilebilir kesinti süreleri içerisinde yeniden çalışır hale getirmek için gerçekleştirilen çalı̧̧malar olarak tanımlanabilmektedir. Kritik iş süreçlerinin daimi olarak çalışır vaziyette bulunması tercih edilen durumdur.

İş Sürekliliği Enstitüsü İş Sürekliliği Yönetimi’ni aşağıdaki gibi tanımlamaktadır [1]:

"İş sürekliliği yönetimi (ISY), operasyonların devam etmesini sağlamak için kullanılan ve ürün ve hizmetlerin önceden tanımlanmış seviyelerde dağıtan bütüncül bir yönetim sürecidir, ayrıca, markalar ile değer-yaratıcı faaliyetleri ve yıkıcı olaylar meydana geldiğinde kilit paydaşların itibarını ve menfaatlerini korur".

"Araştırmacıların ve uygulayıcıların çoğunluğu şimdi İş̧ Sürekliliği Yönetimi’ ni kritik olarak görmekte ve onu organizasyonun sürdürülebilirliği ile pozitif olarak ilişkilendirmektedir" [2]. "Siber dünyada ticari işlem çoğunlukla bilişim teknolojisini kapsasa da, iş sürekliliğinde yalnızca teknolojiyi tek bir çözüm olarak görmek yetersizdir. İşletmenin kullanılabilirliğini ve sürdürülebilirliğini yönetmek, teknoloji, süreç ve insanlar gibi kuruluşa ve kaynaklara yönelik entegre ve dengeli bir yaklaşımı gerektirir" [3].

Günümüzde yapılan araştırmalar felaket, beklenmedik bir durum veya kesinti karşısında maddi ve manevi kayıplar vermemek, kritik süreçlerin devamlılı̆ı̆ını sağlayabilmek amacıyla iş sürekliliği yönetimi sisteminin oldukça önemli olduğunu bir kez daha ortaya koymuştur. Kısa sürede ve etkin olarak müşteri ihtiyaçlarını karşılamak için iş sürekliliğ̣i yönetim sisteminin de kritik başarı faktörlerinin bilinmesi ve ortaya konulmas1 gerekmektedir.

$\mathrm{Bu}$ amaçla; literatür incelemeleri sonucunda, geçmişte yapılan çalışmaların ağırlıklı olarak iş sürekliliği yönetiminin aşamalarını ele aldığı ve özellikle bankalarda uygulama çalışmaları yapıldığı görülmüștür. Ayrıca, önceki çalışmalarda kritik başarı veya başarısızlık faktörlerinin önceliklendirilmesi anket çalışmaları ile yürütülmüştür. $\mathrm{Bu}$ çalışmada ise, iş sürekliliğgi yönetim sistemi ana süreçleri incelenerek iş sürekliliği yönetim sistemindeki kritik başarı faktörleri ele alınmış ve bu faktörlerin AHP yöntemi ile önceliklendirilmesi yapılmıştır.

İş sürekliliği yönetim sistemi, işlerin aksamasına sebep olabilecek bir olayın ardından bir kuruluşun ürün veya hizmet sağlama kabiliyetinin önceden belirlenmiş kabul edilebilir seviyelerde devam etmesi, bir faaliyetin kesintiye uğraması sonucunda kuruluş faaliyetinin devam edebilmesinin temin edilebilmesi için süreçler, prosedürler, kararlar ve faaliyetler oluşturması, başka bir deyişle, kuruluşların krizlerden ve felaketlerden kaçınmasına yardımcı olmak için proaktif ve reaktif planlar yaparak bu gibi durumlar gerçekleştiğinde hızlı bir şekilde olağan duruma geri dönülebilmesini sağlamaya yardımcı olmaktadır. [4]

Felaket anında, iş kesintisi ve beklenmedik durumlarda ticari etkinliklerin ve kritik iş faaliyetlerinin sürdürülebilmesine destek olabilmek, kurumun itibarının zedelenmesini önlemek, işlerin devamlılığını sağlamak için İngiliz Standartlar Enstitüsü (British Standards Institution) tarafindan BS25999 standard1 yayınlanmıştır [5].

BS 25999 yaşam döngüsü, bu standartta ele alınan ve vurgulanması gereken önemli konulardan birisidir (Şekil 1). Bu yaşam döngüsü 6 bileşenden 
oluşmakla birlikte, farklı ölçekte ve türde kuruma uygulanabileceği gibi kurumun kapsamı ve yapısal özelliklerine göre kurumdan kuruma değişiklikler gösterebilmektedir. Program yönetimi, yaşam döngüsünün merkezinde yer alarak iş sürekliliği politikası ile belirlenmiş amaçların gerçekleştirilebilmesi için yapılması gereken çalışmaları tanımlamaktadır.

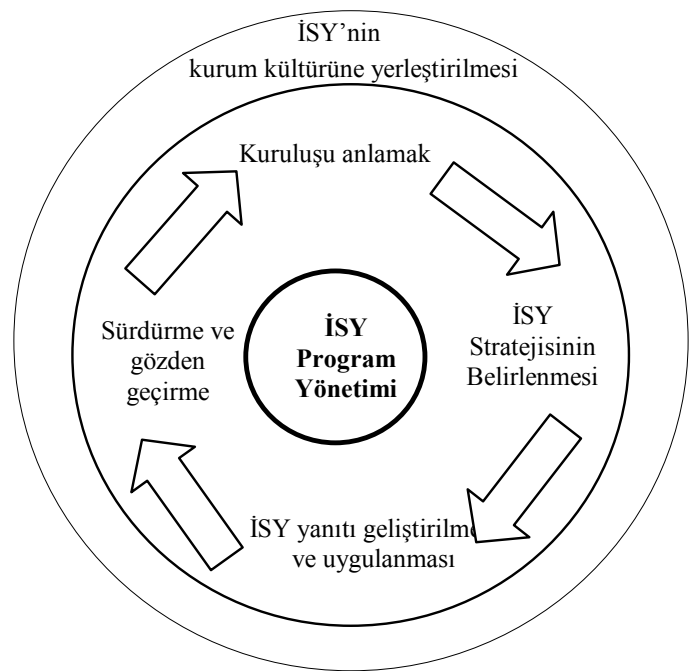

Şekil 1. BS 25999 yaşam döngüsü [5]

PUKO döngüsü organizasyonun İSY'nin kurulması, uygulanması, işletilmesi, izlenmesi, denenmesi, sürekliliğinin sağlanması ve etkinliğinin iyileştirilmesi için BS 25999 İş Sürekliliği Yönetim Sistemi Standardı tarafından kullanır (Çizelge 1).

Çizelge 1. PUKO döngüsü [5]

\begin{tabular}{|l|l|}
\hline Planla & $\begin{array}{l}\text { Organizasyonun tüm politika ve hedefleri } \\
\text { ile uyumlu sonuçlar alabilmek ççin risk } \\
\text { yönetimi ve iş sürekliliğini iyileştirici } \\
\text { politika, amaç, hedef, kontrol, süreç ve } \\
\text { prosedürler oluştur. }\end{array}$ \\
\hline Yap & $\begin{array}{l}\text { İş süreklilik politika, kontrol, süreç ve } \\
\text { prosedürlerini uygula. }\end{array}$ \\
\hline Kontrol et & $\begin{array}{l}\text { İş süreklilik hedef ve politika } \\
\text { performansını izle, gözden geçirme için } \\
\text { yönetime raporla, iyileştirme ya da } \\
\text { değişiklik eylemlerini belirle. }\end{array}$ \\
\hline Uygula & $\begin{array}{l}\text { Gözden geçirme sonuçlarını temel alan } \\
\text { düzeltici ve önleyici faaliyetler ile İSY } \\
\text { sürekliliğini ve iyileşmesini sağla. }\end{array}$ \\
\hline
\end{tabular}

Olağanüstü bir durum ve felaketle karşılaşan kurumlar ciddi mali kayıplar ile birlikte, itibar, müşteri pazar kaybı gibi sorunlar ile karşı karşıya kalabilmektedirler. $\mathrm{O}$ nedenle beklenmeyen bir duruma hazırlıklı olabilmek ve organize şekilde bir plan, program dahilinde kurumun bütününe yayılmış bir kültürle hareket etmek, işletmelerin bu gibi durumlarda esneklik ve hayata geri dönüşü için oldukça önem taşımaktadır.

\section{2. ÖNCEKİ ÇALIŞMALAR}

Fischbacher-Smith [6] makalesinde İSY sürecinin doğasını dikkate almaya ve onu çerçevelemeye çalışmıştır. Yazar, organizasyonların artan ölçek ve karmaşıklığı ile bulundukları coğrafi ölçeğin kriz yaratma potansiyeline sahip olacak acil koşulları oluşturma potansiyeline sahip olduğunu iddia etmektedir. Bileşen seviyesinde herhangi bir başarısızlık olmadığı zaman bile hataların ortaya çıkabileceğine ve bir örgütü kararsız bir duruma sokabilecek bileşenler arasındaki etkileşimin ortaya çıkabileceğine işaret eden FischbacherSmith, İSY sürecinin özünde ve örgütsel performansla olan ilişkilerinde içsel çelişki içerdiğini belirtmiştir. Yazara göre, İSY ve kriz yönetimi, yönetim sürecinde istisna olarak ele alındığı sürece, örgütsel başarısızlıklarla ilgili zorluklar, yöneticilerin ele alması gereken bir konu olmaya devam edecektir.

Torabi ve arkadaşları [7] her organizasyonun çeşitli risklere maruz kalmakta (örneğin, siber saldırılar ve doğal afetlerden kaynaklanan aksamalar) ve bu risklere düzgün bir şekilde cevap vermek için etkili bir risk yönetim sistemi uygulanması gerektiğini düşünmektedirler. İş sürekliliği yönetimi, tanımlanan risklerle başa çıkabilmek için kurumların dayanıklılığını artırmasına olanak tanıyan en yeni risk yönetim çerçevelerinden biridir. Risk değerlendirmesi, bir iş süreklilik yönetim sisteminin ana bölümlerinden biridir. $\mathrm{Bu}$ nedenle çalışmalarında, süreklilik yönetim sisteminin belirli adımları ve gereklilikleri muhasebeleştirilirken, süreklilik yönetim sistemi bağlamında, gelişmiş bir risk değerlendirme çerçevesi de önerilir. Çalışmada, tanımlanmış dört adımlı çerçeve (yani, risklerin tanımlanması, analiz edilmesi, değerlendirilmesi ve cevaplanması) 
dahilinde risk değerlendirme, yönetimi geliştirmek ve kolaylaştırmak için analitik bir teknik setinden faydalanmaktadırlar. Önerilen çerçevenin gerçek bir vaka çalışmasına uygulanmasının sonuçları, bir organizasyonda süreklilik yönetim sistemini uygularken risk değerlendirmesi ve yönetim sürecini etkin bir şekilde ele alabileceğini göstermektedir.

Kulkarni ve arkadaşları [8] çalışmalarında, kriz sonrası İş Sürekliliği Planlaması (İSP) için genel bir çerçeve önermektedir. İSP çerçevesi, İSP için birden fazla planlama yönü, çok aşamalı ve çok sayıda ayrıntılı öğeden oluşur. Çerçeve temel alınarak, örgütler kriz sonrası iş sürekliliği (İS) planlarını tasarlayabilir, bunları uyarlayabilir ve / veya değerlendirebilir. Geleneksel risk yönetimi literatürü, bir krizin bir kuruluşun İS üzerindeki etkisini önleme ve azaltmaya yöneliktir. $\mathrm{Bu}$, genellikle, beklenen risklerin organizasyon üzerindeki etkisini belirleyerek, analiz ederek ve değerlendirerek yapılır. Buna karşın, krizler oluştuğunda örgütlerin ne yapmaları gerektiğine ilişkin literatürde nispeten eksiklikler bulunduğunu öne süren yazarlar gelecekteki çalışmalarında, İSP çerçevesinin endüstriye özgü uzantılarını ele alacaklarını belirtmişlerdir.

Abdullah ve arkadaşları [3], Malezya bilgi temelli bir ekonomi inşa etmeye ve bilgi çağında bilişim teknolojisine daha fazla bağımlı hale gelmeye odaklandığından, kriz veya felaket durumunda iş devamlılığını sağlamak için duyulan ihtiyacın her zamankinden daha önemli hale geldiğini savunmaktadır. Tüm kamu kurumları, beklenmedik kesintilerden sonra operasyonların hızla devam etmesini sağlamak için İSP hazırlamaya çağrılmaktadır. Bununla birlikte, son çalışmalar, ISSY'nin yerine getirilmesine rağmen hizmet kesintilerinin sıklığının oldukça kaygı verici olduğunu göstermiştir. Yazarlar, bu nedenlerden dolayı çalışmalarında, Malezya'nın kamu hizmetinde İSY uygulamasının başarısızlığa uğramasında İSY'nin şimdiki uygulamasını ve başarısızlığa katkıda bulunan faktörleri, yani organizasyonları, insanları, süreçleri ve teknolojiyi araştırmaktadır. Uygulama, 195 bilişim teknolojisi uzmanının katıldığı anketler kullanılarak gerçekleştirilmiştir. Bulgular, örgütlenme, insanlar, süreç ve teknolojinin Malezya Kamu Sektöründe İSY başarısızlığı ile önemli derecede ilişkili olduğunu göstermiştir. Ampirik sonuçlar, insanlar, kültür, teknoloji ve organizasyon politikasının ISSY başarısızlığına katkıda bulunan sürecin kilit faktörlerinin olduğunu ortaya koymaktadır. Bununla birlikte, mevcut ISSY yaklaşımı teknoloji odaklı olmaya yöneliktir ve yalnızca bilişim teknolojisi departmanını içermektedir. ISY uygulaması organizasyonun tüm düzeylerini içermeli ve ilgili tüm kritik iş süreçlerini kapsamalıdır. Bu çalışmanın sonuçları iki anlam ifade etmektedir: Birincisi, İSY başarısızlığına katkıda bulunan faktörün keşfedilmesi ve ikincisi, bu çalışmanın sonuçları ISY başarısızlığına katkıda bulunan faktöre öncelik vermesidir.

Blos ve arkadaşları [9] tarafından geliştirilen modelin bir uzantısı genel bir tedarik zinciri iş sürekliliği çerçevesini geliştirme amacına sahiptir. Bu modelin İran'ın iş birimlerindeki tedarik zinciri risklerinde zaten uygulanmış olması tüm dünyadaki farklı endüstri alanlarına çoğaltılma potansiyelini göstermektedir. Ayrıca, çalışma bu çerçevenin finansal ve pazarlama operasyonel yapılarına genişletilebileceğini göstermektedir.

Sahebjamnia ve arkadaşları [10] işletmelerin gittikçe aksamalara maruz kalmasından; aksamaların doğasını, zamanını ve derecesini tahmin etmenin neredeyse imkansız olmasından, bu nedenle, organizasyonların, yıkıcı olayların sonuçlarına karşı kendilerini korumak için bir karar destek çerçevesi ile donatılmış proaktif bir yaklaşıma ihtiyaç duyduğunu ileri sürmüşlerdir. Yazarlar, çalışmalarında kesinti sonrasında kritik operasyonların verimli ve etkin bir şekilde devam ettirilmesi ve iyileştirilmesi için entegre iş sürekliliği ve felaket kurtarma planlaması için yeni bir çerçeve önermektedir. Önerilen model, karar problemlerine stratejik, taktiksel ve operasyonel seviyede çözümler sunmaktadır. Stratejik düzeyde organizasyonun içeriği ilk kez araştırılmış ve organizasyonel esnekliğin ana özellikleri de tanınmıştır. Daha sonra, iç ve dış kaynakları hem devam ettirme hem de kurtarma planlarına aynı anda ayırmak için çok amaçlı, karışık tamsayı doğrusal programlama modeli formüle edilmiştir. Model kurtarma noktasını en üst düzeye çıkararak 
ve iyileşme süresi hedeflerini en aza indirerek esneklik kaybını kontrol etmeyi amaçlamıştır. Son olarak, operasyonel düzeyde, planların uygulanabilirliğini değerlendirmek için varsayımsal yıkıcı olaylar incelenmektedir.

Abdullah ve arkadaşları [11] çalışmalarında, bilişim hizmetinde başarısızlığa neden olan başlıca faktörlerin insan, süreç ve teknoloji kaynaklı olduğunu vurgulamıştır. Bununla birlikte çalışma, bu unsurların kamu kesimi örgütlerinde servis kesintilerine ne derece katkıda bulunduğunu incelemektedir. Bu çalışma, anketler kullanılarak yapılmıştır. Ampirik sonuçlar, insan faktörünün bilişim hizmet kesintilerinin başlıca nedeni olduğunu, bunun ardından uygun olmayan bir süreç ve teknoloji başarısızlığının kesintiye neden olan faktörler olduğunu ortaya koymaktadır. Buna ek olarak, insanın önemli bir faktör olduğuna ve yönetim tarafından daha fazla dikkat edilmesi gerektiği sonucuna varılmıştır.

Leong ve Marthandan [12] çalışmalarında, başarılı bir İSY sürecinin olanaklarını tanımlamışlardır. $\mathrm{Bu}$ çalışmanın ilk aşaması, İSY süreci üzerinde etkili olan faktörleri anlamayı ve başarılı bir İSY süreci için kavramsal bir model geliştirmeyi içermektedir. Veriler, e-postayla gönderilen anketlerle toplanmıştır. Toplanan veriler kavramsal modeli test etmek için kullanılmış ve analiz yapılmıştır. $\mathrm{Bu}$ çalışmanın bulguları faydalı bilgiler sağlamakta, İSY sürecini uygulayan ve sürdürmekte olan banka yöneticilerine etkili bir şekilde yardımcı olabilmektedir. Bu çalışmanın temel bulguları, teknoloji bileşenlerinin (bilişim teknolojisi kullanılabilirliği ve güvenilirliği, karmaşıklığı ve teknoloji yetkinliği), algılanan İSY faydaları, üst yönetim desteği, İS'yi benimsemeye yönelik dış baskı ve iş ortamının Malezya'daki finansal endüstrideki İSY uygulaması üzerinde olumlu etkileri olduğu yönündedir.

Miniati ve arkadaşları [13] klinik faaliyetlerin, kesin ve tanımlanmış olayların ardışıklığının sonucu olarak görülebileceğini; her bir evrenin çalışma süresini ve olası gecikmeyi içeren bir bekleme süresi ile karakterize edildiğini savunmuşlardır. Yazarlara göre teknoloji bu işlemin sadece bir kısmını yapmakta ve uygun bir iş sürekliliği yönetimi için, yalnızca çalışma yüküne göre minimum sayıda aygıt planlamak yeterli olmamaktadır. Hangi müdahalelerin ve ekstra satın alımın yapılması gerektiğini tanımlamak için tüm süreç hakkında bir risk analizi yapılmalıdır. Olası müdahaleleri değerlendirmek ve tüm sistemi teknolojik arızalara karşı korumak için Markov modelleri ve güvenilirlik mühendisliği yaklaşımları kullanılabilir. Bu çalışmada, tıbbi etkinliği garanti altına almak ve hastanelerde iş sürekliliği yönetim gereksinimlerini yerine getirmek için gerekli olan uygun sayıda cihazı tanımlamak için, risk analizi yaklaşımı ve kuyruk teorisi modeli de dahil olmak üzere önerilen bütünleşik modelin uygulanması üzerine bir vaka çalışması rapor edilmiştir.

Hoong ve Marthandan [14] çalışmalarında, Felaket İyileştirme Planlaması (FIP) ve iş sürekliliği yönetimi konusundaki araştırmaları gözden geçirmektedir. FIP bilişim teknolojisi departmanındaki riskin azaltılmasını dikkate alan bir bilişim süreci olmakla birlikte kesintiler durumunda bilişim sistemlerini kurtarma prosedürünü yerine getirmektedir. FIP ve İSY süreçlerinde var olan faktörleri ve bu faktörlerin güncellenmiş bir çerçeveye nasıl dahil edilebileceğini açıklamakta, ayrıca etkin ve başarılı bir FİP ve İSY uygulaması için açıklayıcı bir çerçeve sunmaktadır.

Goh [15] çalışmasına, SS540: 2008, standart uygulama tarihçesi, İSY kavramına giriş ve SS540: 2008 standardı çerçevesinde özetle başlamaktadır. Singapur'da faaliyet gösteren uluslararası ve yerel işletmeler tarafindan benimsenen Singapur İş Sürekliliği Yönetimi Standardı (İSY)'dir. SS540: 2008'deki İSY çerçevesi, 6 büyük İSY alanı ve dört ana İSY bileşeni içerdiğinden oldukça titizdir. ISY çerçeve matrisi, SS540: 2008'i kapsamlı bir ISY standardı haline getiren bir kapsama alanı sağlamaktadır. Her bir İSY alanının ana bileşenine göndermede bulunulmasına genel bakış ayrıntılı olarak sunulmuştur.

Wong ve arkadaşları [16] çalışmalarında, öncelikle uygulama aşamalarındaki kurumsal kaynak planlama (KKP) uygulama sorunları ve KKP başarısızlık nedenlerine ilişkin güncel literatürü 
incelemişlerdir. Bu KKP sistemlerinin "Neden" ve "nasıl" başarıyla uygulanamayacağını anlamak için birden fazla vaka incelemesi araştırma metodolojisi benimsenmiştir. $\mathrm{Bu}$ vaka analizlerinden farklı paydaşlar (üst düzey yönetim, proje yöneticisi, proje ekibi üyeleri ve KKP danışmanları dahil) görüşülmüş ve üçgenleştirme için KKP uygulama belgeleri gözden geçirilmiş̧ir. Bir KKP yaşam döngüsü çerçevesi, KKP uygulama sürecinin ve ilgili KKP uygulamasının her aşamasındaki problemlerin incelenmesi için uygulanmıştır. On dört kritik başarısızlık faktörü belirlenmiș ve analiz edilmiștir; üç ortak kritik başarısızlık faktörü (zayıf danışman etkinliği, proje yönetimi etkinliği ve iş sürecinin yeniden yapılandırılması kalitesi) incelenmiş ve tartışılmış̧ır.

Cerullo ve Cerullo [17] iç ve dış bilgi güvenliği tehditleri hakkındaki algılamalar da dahil olmak üzere, iş süreklilik planlarının mevcut durumu hakkında yeni bilgiler veren iç ve dış anketleri analiz etmektedir. Şirketler, bilgi teknolojisi altyapısına daha fazla bağımlı hale geldikçe iş kesintileri riskleri artmaktadır. İş sürekliliği planlamasına yönelik kapsamlı bir yaklaşım, iş sistemlerinin tüm önemli iş kesintilerine karşı hafifletmeyi amaçlamaktadır.

\section{MATERYAL VE METOT}

\subsection{Materyal}

Çalı̧̧mada kullanılan materyal anket verileridir. Anketi yanıtlayan uzman, iş sürekliliği yönetim sistemini uygulayan ve risk değerleme ve eksperlik hizmetleri veren bir şirkette çalışan risk mühendisidir. Anketten elde edilen veriler kullanılarak AHP yöntemi ile iş sürekliliği yönetim sistemindeki kritik başarı faktörleri önceliklendirilmiştir. Kritik başarı faktörleri, işletme süreçlerinin başarılı olması için olmazsa olmaz faktörler olarak tanımlanabilmektedir. Çalışmada, 6 adet kritik başarı faktörü ele alınmıştır (Çizelge 2). Ilk beş faktör literatürde yer alırken, sürdürülebilirlik kritik başarı faktörüne ise, daha önceki çalışmalarda yer verilmemiştir. Proje yönetimi iş sürekliliğinin altı ana metodolojisine henüz dahil edilmemiș bir fazdır. Bunun nedeni ise, iş sürekliliğinin organizasyon tarafindan sertifikalandırılması için tamamlanması nedeniyle bu aşamada SS540:2008 standardından düşürülmüş olmasıdır [15]. Proje yönetiminin de kritik başarı faktörü olarak değerlendirilmesi tarafimızca uygun görülmüştür.

Verilerin düzenlenmesinde ve toplanmasinda Microsoft Office Excel 2003 sürümünden yararlanılmıştır.

Çizelge 2. İşs sürekliliği yönetimindeki kritik basari faktörleri

\begin{tabular}{|c|c|c|c|c|c|c|c|}
\hline \multirow[b]{2}{*}{ YAZARLAR } & \multicolumn{6}{|c|}{ KRİTÍK BAŞARI FAKTÖRLERİ } & \multirow[t]{2}{*}{ YIL } \\
\hline & 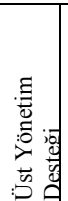 & 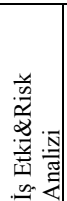 & 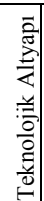 & 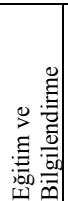 & 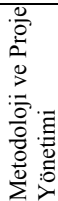 & 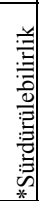 & \\
\hline $\begin{array}{l}\text { Wong, Chau, } \\
\text { Scarbrough \& } \\
\text { Davison[16] }\end{array}$ & $\mathrm{X}$ & & $\mathrm{X}$ & & $\mathrm{X}$ & & 2005 \\
\hline Goh [13] & $\mathrm{X}$ & & $\mathrm{X}$ & $\mathrm{X}$ & $\mathrm{X}$ & & 2009 \\
\hline $\begin{array}{l}\text { Hoong \& Marthandan } \\
\text { [14] }\end{array}$ & $X$ & & $X$ & $\mathrm{X}$ & $\mathrm{X}$ & & 2011 \\
\hline $\begin{array}{l}\text { Abdullah, Noor \& } \\
\text { Ibrahim [3] }\end{array}$ & $\mathrm{X}$ & & $X$ & $\mathrm{X}$ & $\mathrm{X}$ & & 2015 \\
\hline Fischbacher-Smith [6] & $\mathrm{X}$ & $\mathrm{X}$ & & & & & 2017 \\
\hline *Yazarlar tarafindan & & & & & & $\mathrm{X}$ & 2018 \\
\hline
\end{tabular}

\subsection{Metodoloji}

Çalışmada kullanılan metodoloji aşağıdaki adımlardan oluşmaktadır;

i. Çalışmanın amaçları doğrultusunda iş sürekliliği planlaması, iş sürekliliği yönetimi, AHP uygulamaları konularında geniş bir literatür taraması yapılması,

ii. Literatürden elde edilen sonuca göre çalıșmanın amacını da dikkate alarak, hazırlanacak olan sistemin kavramsal bir veri akış modelinin oluşturulması,

iii. İSY, AHP ve benzer uygulamaların incelenmesi,

iv. İSY kritik başarı faktörlerinin belirlenmesi,

v. Yeterli etkinlikte sorularnn kapsayan anket hazırlanmas1,

vi. İSY uygulanan bir işletme seçilerek hazırlanan anketin uzmana uygulanması, 
vii. Anket sonuçlarının AHP metodu ile analiz edilerek İSY'deki kritik başarı faktörlerinin önceliklendirilmesi,

viii. AHP yaklaşımının iş sürekliliği yönetimindeki kritik başarı faktörleri modeline uygulanmasi sonucunda elde edilen bulguların irdelenmesi, bulgulardan yola çıkarak, sonuçların ve geleceğe yönelik önerilerin ortaya konulması çalışmanın metodolojisini göstermektedir.

\subsection{Metot}

\subsubsection{Analitik Hiyerarşi Prosesi (AHP)}

AHP, 1977 yılında Thomas L. Saaty tarafindan geliştirilen "Çok Kriterli Karar Verme" (ÇKKV) aracıdır. Sürece somut nicel kiterlerin yanı sıra soyut nitel kriterlerin de dahil edilmesi mümkündür [18]. AHP kullanılan karar problemlerinin çözümü dört adımdan oluşmaktadır. Bunlar [19];

Adım 1: Birbirleri ile ilişkili kriterlerin hiyerarşisi içerisinde karar probleminin parçalara ayrılarak karar hiyerarşisinin kurulması,

Adım 2: Kriterlerin ikili karşılaştırmalarına göre giriş verilerinin toplanması,

Adım 3: Kriterlerin göreceli ağırlıklarını tahmin etmek için "özdeğer matrisi” yönteminin kullanılması,

Adım 4: Karar alternatiflerinin değerlendirmelerine ulaşmak için kriterlerin nispi ağırlıkları kümelenmektedir.

Karşılaştırma yapılırken kriterlerin birbirinden ne kadar önemli olduğunu gösteren bir ölçeğe ihtiyaç duyulmaktadır [20]. Çizelge 3' te AHP için önem düzeyleri sıralanmıştır.

Son olarak yargıların tutarlı olup olmadığını ölçmek amacıyla tutarlılık oranı hesaplanmaktadır. Eğer bu oran 0,1'den büyük ise yargıların tutarsız olduğu sonucuna varılmaktadır [22].

\section{ARAŞTIRMA BULGULARI VE TARTIŞMA}

\subsection{Karar Probleminin Tanımı}

Karar problemi, iș sürekliliği yönetim sistemindeki kritik başarı faktörlerinin öncelik düzeylerinin ortaya konulmasını sağlayan bir sistem tasarlamaktır.

Çizelge 3. AHP önem düzeyleri [21]

\begin{tabular}{|c|c|c|}
\hline : & 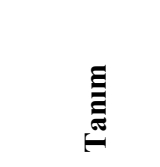 & 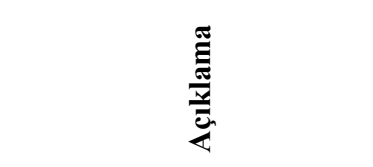 \\
\hline 1 & Eşit Önem & $\begin{array}{l}\text { İki faaliyet amaca eşit } \\
\text { düzeyde katkıda bulunur. }\end{array}$ \\
\hline 3 & $\begin{array}{l}\text { Birinin } \\
\text { diğerine } \\
\text { göre çok az } \\
\text { önemli } \\
\text { olmas1 }\end{array}$ & $\begin{array}{l}\text { Tecrübe ve yargı bir faaliyeti } \\
\text { diğerine çok az tercih ettirir. }\end{array}$ \\
\hline 5 & $\begin{array}{l}\text { Kuvvetli } \\
\text { derecede } \\
\text { önemli }\end{array}$ & $\begin{array}{l}\text { Tecrübe ve yargi bir faaliyeti } \\
\text { diğerine çok kuvvetli bir } \\
\text { derecede tercih ettirir. }\end{array}$ \\
\hline 7 & $\begin{array}{l}\text { Çok } \\
\text { kuvvetli } \\
\text { düzeyde } \\
\text { önemli }\end{array}$ & $\begin{array}{l}\text { Bir faaliyet güçlü bir şekilde } \\
\text { tercih edilir ve baskınlığı } \\
\text { uygulamada rahatlıkla } \\
\text { görülür. }\end{array}$ \\
\hline 9 & $\begin{array}{l}\text { Aşırı } \\
\text { derecede } \\
\text { önemli }\end{array}$ & $\begin{array}{l}\text { Bir faaliyetin diğerine tercih } \\
\text { edilmesine ilişkin kantlar } \\
\text { çok büyük güvenilirliğe } \\
\text { sahiptir. }\end{array}$ \\
\hline $2,4,6,8$ & $\begin{array}{l}\text { Orta } \\
\text { Değerler }\end{array}$ & $\begin{array}{l}\text { Uzlaşma gerektiğinde } \\
\text { kullanmak üzere yukarıda } \\
\text { listelenen yargılar arasına } \\
\text { düşen değerler. }\end{array}$ \\
\hline
\end{tabular}

\subsection{Hiyerarşik Yapının Oluşturulması}

Hiyerarşi yapıyı oluşturacak amaç, iș sürekliliği yönetiminde kritik başarı faktörü seçimidir. Çalışmada, "planlama, tedbir ve sorumluluk" olmak üzere 3 adet ana kriter ve alt kriterleri belirtilmiştir. Değerlendirme iş sürekliliği yönetimi konusunda uzman risk mühendisi tarafindan yapılmıştır. Ana kriterler, problemin amacına göre 
iş sürekliliği yönetiminde kritik başarı faktörü önceliklendirmeyi sağlayacak şekilde oluşturulmuş ve planlama, tedbir, sorumluluk şeklinde ana kriterler ele alınmıştır.

Tanımlanan tüm ana kriter ve alt kriterler Çizelge 4'te görülmektedir. Problemin oluşturulan hiyerarşik modeli ise Şekil 2'de yer almaktadır. Burada ele alınan problemin amacı, belirlenen ana kriterler ve alt kriterler için AHP modeli görülmektedir.

Çizelge 4. Tanımlanan ana kriter ve alt kriterler

\begin{tabular}{|l|l|l|}
\hline \multirow{2}{*}{} & \multirow{2}{*}{} & İş Sürekliliği Planı \\
& \multirow{2}{*}{ Tatbikat ve İyileştirme } \\
Planı
\end{tabular}

Problemin karar hiyerarşisi oluşturulurken planlama, tedbir ve sorumluluk olmak üzere 3 ana kriter ve bu kriterlerle ilişkili on üç alt kriter kullanılmıştır (Şekil 2). Şekilde seviye 3 ve seviye 4 arasında gösterilen çapraz çizgiler alt kriterlerin önceliklerine göre hangi karar alternatiflerinin seçilebileceğini belirtmektedir.

\subsection{Ana Kriteler Arası İkili Karşılaştırma Matrislerinin Oluşturulması}

Çalışmanın bu bölümünde ikili karşılaştırma matrislerine yer verilecektir. Öncelikle ana kriterler arasında ikili karşılaştırma matrisleri oluşturularak ana kriterler arasındaki önem düzeyleri belirlenecektir (Çizelge 5).

\subsection{Alt Kriterler Arası İkili Karşılaştırma Matrislerinin Oluşturulması}

Ana kriterlerden elde edilen önem düzeyleri alt kriterler arası karşılaştırma matrislerinin ağırlıkları olarak ele alınacaktır (Çizelge 6-8).

Çizelge 5. İşs sürekliliği yönetiminde kritik başari faktörü önceliklendirme amaci için ana kriterler arasi karşilaştirma matrisi ve önem düzeyleri

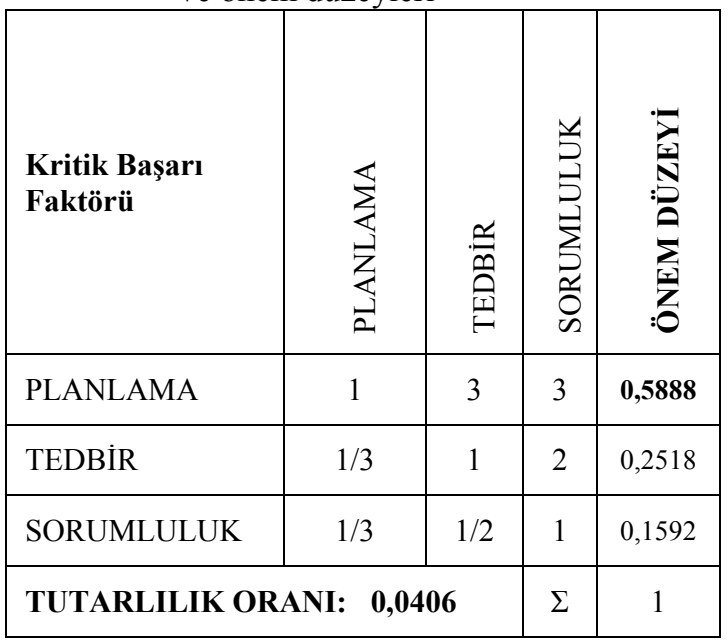

\subsection{Karar Alternatifleri İçin İkili Karşılaştırma Matrislerinin Olușturulması}

Alt kriterler arası karşılaştırma matrisleri sonucunda bulunan değerler ana kriterlerin önem düzeyleri çarpılarak ağırlık değerler elde edilmiştir (Çizelge 9).

Alt kriterlerin ikili karşılaştırılmasından sonra her bir alternatif tüm alt kriterler açısından değerlendirilecektir. Karşılaştırmalar ele alınırken uzman görüşü dikkate alınmıştır (Çizelge 10, 11). 


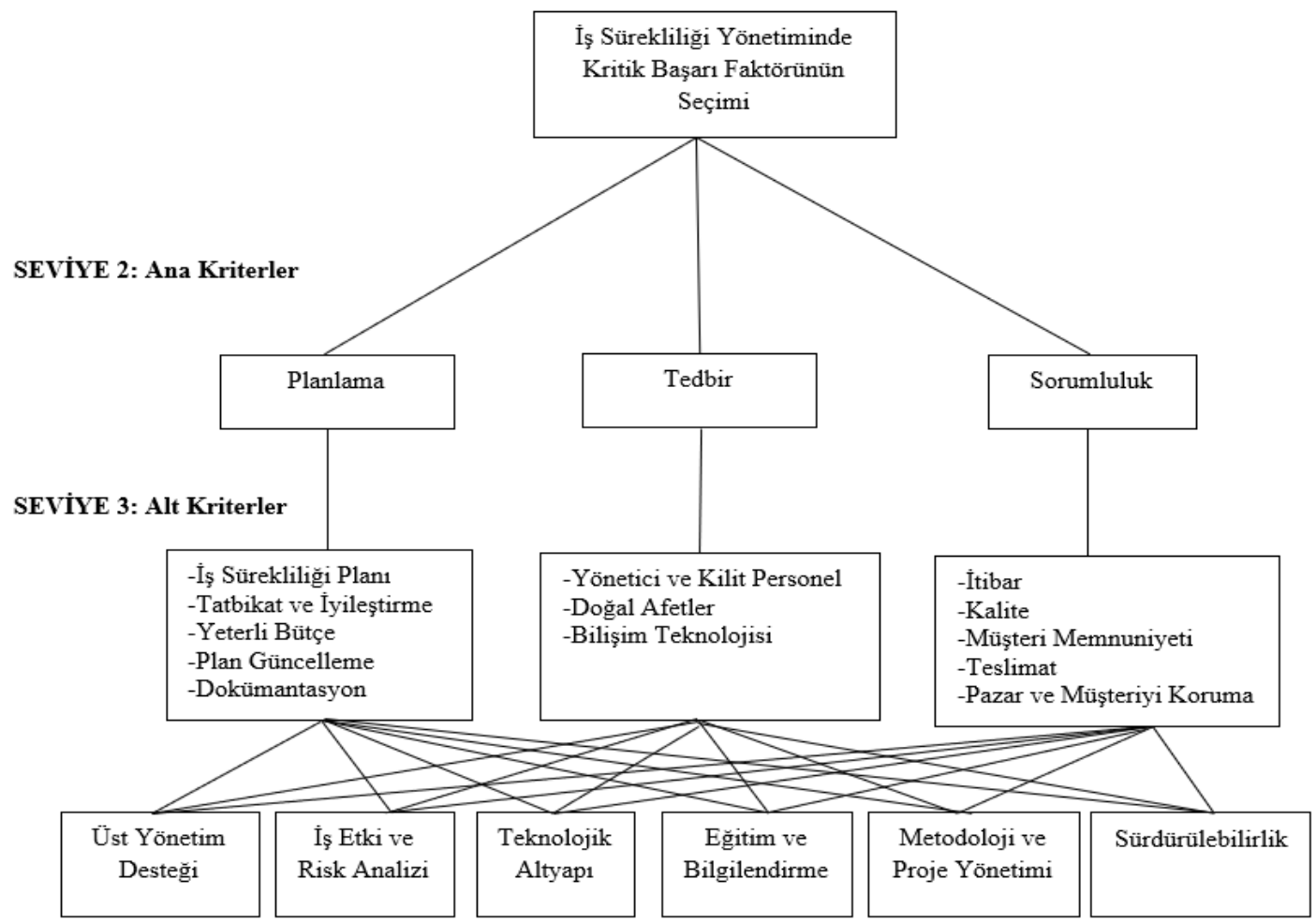

SEVIYE 4: Karar Alternatifleri

Şekil 2. AHP karar hiyerarşisi

Çizelge 6. Planlama ana kriterine göre alt kriterler karşılaştırma matrisi ve önem düzeyleri

\begin{tabular}{|l|c|c|c|c|c|c|}
\hline PLANLAMA & $\begin{array}{c}\text { İ̧ş̧ } \\
\text { Planı }\end{array}$ & $\begin{array}{c}\text { Tatbikat ve } \\
\text { İyileştirme }\end{array}$ & $\begin{array}{c}\text { Yeterli } \\
\text { Bütçe }\end{array}$ & $\begin{array}{c}\text { Plan } \\
\text { Güncelleme }\end{array}$ & $\begin{array}{c}\text { Dokümanta } \\
\text { syon }\end{array}$ & $\begin{array}{c}\text { ÖNEM } \\
\text { DÜZEYI }\end{array}$ \\
\hline $\begin{array}{l}\text { İş Sürekliliği } \\
\text { Planı }\end{array}$ & 1 & $1 / 2$ & $1 / 5$ & $1 / 2$ & $1 / 6$ & 0,0570 \\
\hline $\begin{array}{l}\text { Tatbikat ve } \\
\text { İyileştirme }\end{array}$ & 2 & 1 & $1 / 6$ & $1 / 5$ & $1 / 6$ & 0,0649 \\
\hline Yeterli Bütçe & 5 & 6 & 1 & 3 & 2 & $\mathbf{0 , 4 0 0 4}$ \\
\hline Plan Güncelleme & 2 & 5 & $1 / 3$ & 1 & $1 / 5$ & 0,1436 \\
\hline Dokümantasyon & 6 & 6 & $1 / 2$ & 4 & 1 & 0,3338 \\
\hline
\end{tabular}

Çizelge 7. Tedbir ana kriterine göre alt kriterler karşilaştirma matrisi ve önem düzeyleri

\begin{tabular}{|l|c|c|c|c|}
\hline & Yönetici ve Kilit Personel & Doğal Afetler & $\begin{array}{l}\text { Bilişim } \\
\text { Teknolojisi }\end{array}$ & $\begin{array}{l}\text { ÖNEM } \\
\text { DÜZEYİ }\end{array}$ \\
\hline Yönetici ve Kilit Personel & 1 & 2 & $1 / 3$ & 0,2518 \\
\hline Doğal Afetler & $1 / 2$ & 1 & $1 / 3$ & 0,1592 \\
\hline Bilişim Teknolojisi & 3 & 3 & 1 & $\mathbf{0 , 5 8 8 8}$ \\
\hline TUTARLILIK ORANI: & $\mathbf{0 , 0 4 0 6}$ & & TOPLAM & 1 \\
\hline
\end{tabular}


Çizelge 8. Sorumluluk ana kriterine göre alt kriterler karşilaştirma matrisi ve önem düzeyleri

\begin{tabular}{|l|c|c|c|c|c|c|}
\hline SORUMLULUK & İtibar & Kalite & $\begin{array}{c}\text { Müşteri } \\
\text { Memnuniyeti }\end{array}$ & Teslimat & $\begin{array}{c}\text { Pazar ve } \\
\text { Müşteriyi Koruma }\end{array}$ & $\begin{array}{c}\text { ÖNEM } \\
\text { DÜZEYI }\end{array}$ \\
\hline İtibar & 1 & 7 & 1 & 1 & 4 & $\mathbf{0 , 3 3 7 1}$ \\
\hline Kalite & $1 / 7$ & 1 & $1 / 4$ & 1 & 1 & 0,0922 \\
\hline Müssteri Memnuniyeti & 1 & 4 & 1 & 2 & 3 & 0,3076 \\
\hline Teslimat & 1 & 1 & $1 / 2$ & 1 & 1 & 0,1589 \\
\hline $\begin{array}{l}\text { Pazar ve Müşteriyi } \\
\text { Koruma }\end{array}$ & $1 / 4$ & 1 & $1 / 3$ & 1 & 1 & 0,1039 \\
\hline TUTARLILIK ORANI: & $\mathbf{0 , 0 7 1 3}$ & & TOPLAM & 1 \\
\hline
\end{tabular}

Çizelge 9. Alt kriterlerin önem değerleri

\begin{tabular}{|c|l|c|c|}
\hline \multirow{4}{*}{ ANA KRITERLER } & \multicolumn{1}{|c|}{ ALT KRITERLER } & DEĞERLER & ÖNEM DÜZEYLERI \\
\hline \multirow{4}{*}{ PLANLAMA (0,5888) } & İş Sürekliliği Planı & 0,0570 & 0,0335 \\
\cline { 2 - 4 } & Tatbikat ve İyileştirme & 0,0649 & 0,0382 \\
\cline { 2 - 4 } & Yeterli Bütçe & 0,4004 & $\mathbf{0 , 2 3 5 8}$ \\
\cline { 2 - 4 } & Plan Güncelleme & 0,1436 & 0,0846 \\
\cline { 2 - 4 } & Dokümantasyon & 0,3338 & 0,1966 \\
\hline \multirow{3}{*}{ TEDBİR (0,2518) } & Yönetici ve Kilit Personel & 0,2518 & 0,0634 \\
\cline { 2 - 4 } & Doğal Afetler & 0,1592 & 0,0401 \\
\cline { 2 - 4 } & Bilişim Teknolojisi & 0,5888 & $\mathbf{0 , 1 4 8 3}$ \\
\hline \multirow{3}{*}{$\begin{array}{c}\text { SORUMLULUK } \\
\text { (0,1592) }\end{array}$} & Itibar & 0,3371 & 0,0536 \\
\cline { 2 - 4 } & Kalite & 0,0922 & 0,0146 \\
\cline { 2 - 4 } & Müşteri Memnuniyeti & 0,3076 & 0,0489 \\
\cline { 2 - 4 } & Teslimat & 0,1589 & 0,0253 \\
\cline { 2 - 4 } & Pazar ve Müşteriyi Koruma & 0,1039 & 0,0165 \\
\hline & & TOPLAM & 1 \\
\hline
\end{tabular}

Elde edilen tüm tutarll1ık oranları 0,1 'den küçük olduğu için yargıların tutarlı olduğu sonucuna varılmaktadır.
Çizelge 10 ve Çizelge $11^{\prime}$ 'de örnek olması açısından karar alternatiflerinin iş sürekliliği planı ve tatbikat ve iyileştirme alt kriterlerine göre matrisleri gösterilmiştir.

Çizelge 10. İş sürekliliği plani alt kriterine göre iş sürekliliği yönetiminde kritik başari faktörü seçim alternatiflerinin karşilaştirma matrisi ve önem düzeyleri

\begin{tabular}{|c|c|c|c|c|c|c|c|}
\hline İŞ SÜREKLİLİĞİ PLANI & 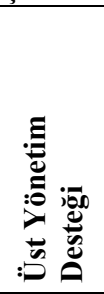 & 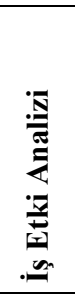 & 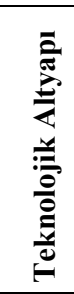 & 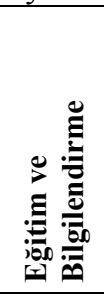 & 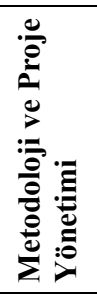 & 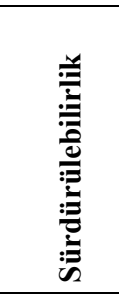 & $\begin{array}{c}\text { ÖNEM } \\
\text { DÜZEYI }\end{array}$ \\
\hline Üst Yönetim Desteği & 1 & 7 & 1 & 1 & 4 & 1 & 0,2523 \\
\hline İş Etki Analizi & $1 / 7$ & 1 & $1 / 4$ & 1 & 1 & $1 / 4$ & 0,0645 \\
\hline Teknolojik Altyap 1 & 1 & 4 & 1 & 2 & 3 & 1 & 0,2292 \\
\hline Eğitim ve Bilgilendirme & 1 & 1 & $1 / 2$ & 1 & 1 & $1 / 4$ & 0,1072 \\
\hline Metodoloji ve Proje Yönetimi & $1 / 4$ & 1 & $1 / 3$ & 1 & 1 & $1 / 4$ & 0,0720 \\
\hline Sürdürülebilirlik & 1 & 4 & 1 & 4 & 4 & 1 & 0,2745 \\
\hline TUTARLILIK ORANI: & 0,0494 & & & & & Toplam & 1 \\
\hline
\end{tabular}


Çizelge 11. Tatbikat ve iyileştirme alt kriterine göre iş sürekliliği yönetiminde kritik başari faktörü seçim alternatiflerinin karşilaştirma matrisi ve önem düzeyleri

\begin{tabular}{|c|c|c|c|c|c|c|c|}
\hline $\begin{array}{l}\text { TATBİKAT ve } \\
\text { IYYILEŞTIRMME }\end{array}$ & 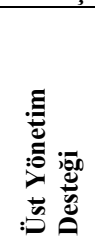 & 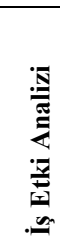 & 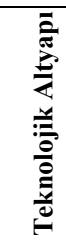 & 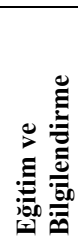 & 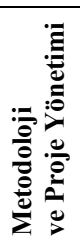 & 范 & $\begin{array}{c}\text { ÖNEM } \\
\text { DÜZEYI }\end{array}$ \\
\hline Üst Yönetim Desteği & 1 & $1 / 4$ & $1 / 4$ & $1 / 4$ & 7 & $1 / 5$ & 0,0765 \\
\hline İş Etki Analizi & 4 & 1 & 1 & 1 & 8 & 2 & 0,2459 \\
\hline Teknolojik Altyapı & 4 & 1 & 1 & 1 & 7 & 2 & 0,2415 \\
\hline Eğitim ve Bilgilendirme & 4 & 1 & 1 & 1 & 7 & 2 & 0,2415 \\
\hline Metodoloji ve Proje Yönetimi & $1 / 7$ & $1 / 8$ & $1 / 7$ & $1 / 7$ & 1 & $1 / 8$ & 0,0261 \\
\hline Sürdürülebilirlik & 5 & $1 / 2$ & $1 / 2$ & $1 / 2$ & 8 & 1 & 0,1680 \\
\hline TUTARLILIK ORANI: & \multicolumn{5}{|l|}{0,0584} & Toplam & 1 \\
\hline
\end{tabular}

Benzer şekilde tüm alt kriterler açısından yapılan matrisler sonucunda Çizelge 12'ye ulaşılmıştır. Çizelge 12 'de ana kriterlerin önem düzeyleri ile ağırlıklandırılmış olan alt kriterlerin önem düzeyleri her bir alternatifin önem düzeyleri ile çarpılmış ve son önem düzeyleri elde edilmiştir. Alternatiflerin önem düzeyleri ise, kendi arasında toplanarak karar vermemize yardımcı olacak olan ağırlık değerlerine ulaşılmıştır [23].

Çizelge 12. İş sürekliliği yönetiminde öncelikli kritik başari faktörü seçim probleminde alt kriter ve alternatiflerin öncelik değerleri

\begin{tabular}{|l|l|l|l|l|l|l|l|l|r|r|r|r|r|}
\hline & & & & & & & \\
\hline
\end{tabular}

\subsection{Bulguların Önceki Çalışmalar ile Karşılaştırılması}

Uzman görüşü ile elde edilmiş sonuçlar önceki çalışmalar ile uyumluluk göstermektedir. Önceki çalışmalar etkili, net ve dokümante edilmiş süreç, üst yönetim desteği, yetenekli takım arkadaşları, yeterli bilişim teknolojisi altyapısının iş sürekliliği yönetimi için son derece önem taşımakta olduğunu belirtmektedir [3, 6, 14, 16]. Ayrica, Abdullah ve 
arkadaşları da [3] süreç ve insanın iş sürekliliği yönetimi açısından en önemli faktörler olduğunu belirtmektedir. Çalışmalarında Malezya'nın kamu hizmetinde İSY uygulamasının başarısızlığa uğramasında ISY'nin şimdiki uygulamasını ve başarısızlığa katkıda bulunan faktörleri, yani organizasyonları, insanları, süreçleri ve teknolojiyi araştırmaktadır. Bulgular, örgütlenme, insanlar, süreç ve teknolojinin Malezya Kamu Sektöründe ISY başarısızlığı ile önemli derecede ilişkili olduğunu göstermiştir. Sonuçlar araştırmamız ile uyumluluk göstermektedir.

Hoong ve Marthandan [14] çalışmalarında, başarılı bir ISY sürecinin gereklerini tanımlamışlardır. İlgili çalışmanın temel bulguları; teknoloji bileşenlerinin (Bilişim teknolojisi kullanılabilirliği ve güvenilirliği, karmaşıklığı ve teknoloji yetkinliği), algılanan İS faydaları, üst yönetim desteği, İS'ni benimsemeye yönelik dış baskı ve iş ortamının Malezya'daki finansal endüstrideki İSY uygulaması üzerinde olumlu etkileri olduğu yönündedir. Bizim çalışmamızda da bilişim teknolojisi ikinci önemli faktör olarak çıkmış ve belirtilen kaynağı desteklemektedir. Ancak literatürde bizim çalışmamızda yer alan kriterlerin önceliklendirilmesi yer almadığından kriterlerin sıralaması konusunda bulgularımız kaynaklar ile ilişkilendirilememiştir.

Literatürde söz edilmeyen ve çalışmada karar alternatiflerine ilave edilen "Sürdürülebilirlik" kritik başarı faktörünün yüzde 17,5 ile dördüncü sırada yer alması ve birinci sıradaki "metodoloji ve proje yönetimi" faktörü ile arasında sadece 2,2 puan farkı olması da önemli bir bulgudur.

\section{SONUÇLAR VE ÖNERİLER}

\subsection{Sonuçlar}

Bu çalışmada üç ana kriter ve on üç alt kriter ile iş sürekliliği yönetiminde altı kritik başarı faktörü arasında önceliklendirme problemi için oluşturulan AHP modeli sonucu Çizelge 13'de gösterilmektedir. AHP hesaplaması sonucunda 0,197 ağırlık ile "metodoloji ve proje yönetimi" birinci öncelikli bulunmuştur. Ardından, teknolojik altyapı alternatifi ikinci $(0,194)$; üst yönetim desteği üçüncü $(0,186)$; sürdürülebilirlik dördüncü $(0,175)$; iş etki analizi\&risk analizi beşinci $(0,129)$; eğitim ve bilgilendirme altıncı $(0,119)$ sirada yer almıştır.

Çizelge 13. İş sürekliliği yönetiminde öncelikli kritik başari faktörü seçim probleminde alternatiflerin öncelik değerleri

\begin{tabular}{|l|l|l|}
\hline ÖNCELİK DÜZEYI & ALTERNATIFLER & ÖNEM DÜZEYİ \\
\hline Birinci Öncelik & Metodoloji ve Proje Yönetimi & 0,197 \\
\hline İkinci Öncelik & Teknolojik Altyap1 & 0,194 \\
\hline Üçüncü Öncelik & Üst Yönetim Desteği & 0,186 \\
\hline Dördüncü Öncelik & Sürdürülebilirlik & 0,175 \\
\hline Beşinci Öncelik & İş Etki Analizi\&Risk Analizi & 0,129 \\
\hline Altıncı Öncelik & Eğitim ve Bilgilendirme & 0,119 \\
\hline TOPLAM & $\mathbf{1}$ \\
\hline
\end{tabular}

\section{2. Öneriler}

Yapılan analizler sonucunda, çalışmanın bulgularına göre iş sürekliliği yönetiminde kritik başarı faktörleri konusunda özel önerilerde bulunmak mümkündür. $\mathrm{Bu}$ öneriler;

Sektöre yönelik öneriler: Çalışmadaki AHP değerlendirmesi hizmet sektöründe (sigorta) görev alan bir uzman tarafindan doldurulmuştur.
Değerlendirme hizmet sektörüne göre yapılmıştır. Hizmet sektörü için birinci önceliğe sahip olan bir kritik başarı faktörü, üretim sektörü açısından bakıldığında ilk öncelik olmayabilmektedir. Bu nedenle bundan sonraki çalışmalarda AHP değerlendirmesi yapacak olan uzman üretim sektöründen seçilip sonuçlar karşılaştırılabilir.

İş sürekliliği yönetimine yönelik öneriler: İş kesintisine neden olan yeni faktörlerin 
keşfedilmesine olanak sağlayan daha detaylı araştırmaların yapılarak faktörlerin önceliklerinin belirlenip sadece tek bir departmana ya da tek bir endüstriye bağlı kalınmadan her alanda iş sürekliliği yönetimi uygulanması gerektiğini vurgulayan bir çalışma yapılabilir.

\section{KAYNAKLAR}

1. Estall, H., 2012. Business Continuity Management Systems: Implementation and Certification to ISO 22301. BCS, The Chartered Institute.

2. Järveläinen, J., 2013. IT Incidents and Business Impacts: Validating a Framework for Continuity Management in Information Systems. International Journal of Information Management, 33(3), 583-590.

3. Abdullah, N.A.S., Noor, N.L.M., Ibrahim, E.N.M., 2015. Contributing Factor to Business Continuity Management (Bcm) Failure-a Case of Malaysia Public Sector.

4. https://www.tse.org.tr/tr/icerikdetay/2044/1064 /ts-iso-22301-is-surekliligi-yonetim-

sistemi.aspx. Erişim tarihi:1 Şubat, 2017.

5. Türkiye Bilişim Derneği, Kamu Bilgi İşlem Merkezleri Yöneticileri Birliği Kamu Bilişsim Platformu \& XIV. K.B.P. (2012), İş Sürekliliği Yönetimi Çalışma Grubu Raporu, 3. Ara Rapor, TBD/Kamu-BIB/2012-ÇG2.

6. Fischbacher-Smith, D., 2017. When Organisational Effectiveness Fails: Business Continuity Management and the Paradox of Performance. Journal of Organizational Effectiveness: People and Performance, 4(1), 89-107.

7. Torabi, S.A., Soufi, H.R., Sahebjamnia, N., 2014. A New Framework for Business Impact Analysis in Business Continuity Management (with a case study). Safety Science, 68, 309-323.

8. Kulkarni, S., Hidding, G.J., Cicekoglu, S., 2015. A Framework for Post-Crisis Business Continuity Plans. In System Sciences (HICSS), $201548^{\text {th }}$ Hawaii International Conference on, 143-152. IEEE.

9. Blos, M.F., Hoeflich, S.L., Miyagi, P.E., 2015. A General Supply Chain Continuity
Management Framework. Procedia Comput Sci 55, 1160-1164.

10. Sahebjamnia, N., Torabi, S.A., Mansouri, S.A., 2015. Integrated Business Continuity and Disaster Recovery Planning: Towards Organizational Resilience. European Journal of Operational Research, 242(1), 261-273.

11. Abdullah, N.A.S., Noor, N.L.M., Ibrahim, E.N.M., 2014. Information Technology Service Management (ITSM): Contributing Factors to IT Service Disruptions-a Case of Malaysia Public Service Agencies, 185, In PACIS.

12. Leong, L.H., Marthandan, G., 2013. Enablers of Successful Business Continuity Management Process. Australian Journal of Basic and Applied Sciences, 7(10), 86-97.

13. Miniati, R., Cecconi, G., Dori, F., Frosini, F., Iadanza, E., Gentili, G.B., Gusinu, R., 2013. A Queueing Theory Based Model for Business Continuity in Hospitals. In $201335^{\text {th }}$ Annual International Conference of the IEEE Engineering in Medicine and Biology Society (EMBC), 922-925, IEEE.

14. Hoong, L.L., Marthandan, G., 2011. Factors Influencing the Success of the Disaster Recovery Planning Process: A Conceptual Paper. In Research and Innovation in Information Systems (ICRIIS), 2011 International Conference on, 1-6, IEEE.

15. Goh, M.H., 2009. BCM Implementation for Organizations Using the Singapore Standard SS540:2008. BCM Institute-White Paper, (Jan), 1-5.

16. Wong, A., Scarbrough, H., Chau, P., Davison, R., 2005. Critical Failure Factors in ERP Implementation. Pacis 2005 Proceedings, 40.

17. Cerullo, V., Cerullo, M.J., 2004. Business Continuity Planning: a Comprehensive Approach. Information Systems Management, 21(3), 70-78.

18. Badri, M.A., 2001. A Combined AHP-GP Model for Quality Control Systems. International Journal of Production Economics, 72(1), 27-40.

19.Zahedi, F., 1986. The Analytic Hierarchy Process-a Survey of the Method and its Applications. Interfaces, 16(4), 96-108. 
20. Saaty, T.L., 2008. Decision Making with the Analytic Hierarchy Process. International journal of Services Sciences, 1(1), 83-98.

21. Saaty, T.L., Sodenkamp, M., 2010. The Analytic Hierarchy and Analytic Network Measurement Processes: the Measurement of Intangibles. In Handbook of Multicriteria Analysis, 91-166, Springer, Berlin, Heidelberg.

22. Coyle, G., 2004. The Analytic Hierarchy Process (AHP). Practical Strategy: Structured Tools and Techniques, 1-11.

23. Özçifçi, V., Arsu, T., 2013. Lojistik Servis Sağlayıcısı Seçiminde AHP uygulaması. Sosyal ve Beşeri Bilimler Dergisi, 5(1), 524-536. 